\title{
Identifying the use and barriers to the adoption of renal tumour biopsy in the management of small renal masses
}

Patrick O. Richard ${ }^{1}$; Lisa Martin² ${ }^{2}$ Luke T. Lavallée $^{3}$; Philippe D. Violette ${ }^{4}$; Maria Komisarenko²; Andrew J Evans ${ }^{5}$; Kunal Jain² ${ }^{2}$ Michael A.S. Jewett ${ }^{2}$; Antonio Finelli ${ }^{2}$ ${ }^{1}$ Division of Urology, Department of Surgery, Centre Hospitalier Universitaire de Sherbrooke, Centre de Recherche du CHUS and the University of Sherbrooke, Sherbrooke, QC; ${ }^{2}$ Division of Urology, Departments of Surgery, Princess Margaret Cancer Centre, University Health Network and the University of Toronto, Toronto, ON; ${ }^{3}$ Division of Urology, Department of Surgery, The Ottawa Hospital, Ottawa Hospital Research Institute and University of Ottawa, Ottawa, ON; ${ }^{4}$ Division of Urology, Department of Surgery, Woodstock General Hospital and Division of Urology, Department of Surgery, McMaster University, Hamilton, ON; ${ }^{5}$ Department of Laboratory Medicine and Pathobiology, Toronto General Hospital, University Health Network and the University of Toronto, Toronto, ON; Canada

Funding: The study was funded in part by the Canadian Urological Association Scholarship Foundation and the Kidney Cancer Research Network of Canada

Presentation: The abstract was presented at the 2017 Annual American Urological Association meeting and at the 2017 Annual Canadian Urological Association meeting.

Cite as: Can Urol Assoc J 2018 April 6; Epub ahead of print. http://dx.doi.org/10.5489/cuaj.5065

\section{Published online April 6, 2018}

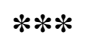

\section{Abstract}

Introduction: Renal tumour biopsies (RTBs) can provide the histology of small renal masses (SRMs) prior to treatment decision making. However, many urologists are reluctant to use RTB as a standard of care. This study characterizes the current use of RTB in the management of SRMs and identifies barriers to a more widespread adoption.

Methods: A web-based survey was sent to members of the Canadian and Quebec Urological Associations who had registered email address ( $n=767)$ in June 2016. The survey examined physicians practice patterns, RTB utilization, and potential barriers to RTB. Chisquared tests were used to assess for differences between respondents.

Results: The response rate was 29\% ( $n=223)$, of which 188 respondents were eligible. A minority of respondents (12\%) perform RTB in $>75 \%$ of cases, while $53 \%$ never perform or perform RTB in $<25 \%$ of cases. Respondents with urological oncology fellowship training were more likely to request a biopsy than their colleagues without such training. The most 
frequent management-related reason for not using routine RTB was a belief that biopsy won't alter management, while the most frequent pathology-related reason was the risk of obtaining a false-negative or a non-diagnostic biopsy.

Conclusions: Adoption of RTBs remains low in Canada. Concerns about the accuracy of RTB and its ability to change clinical practice are the largest barriers to adoption. A knowledge translation strategy is needed to address these concerns. Future studies are also required in order to define where RTB is most valuable and how to best to implement it.

\section{Introduction}

Increased use and improved accuracy of abdominal imaging over the last decade has increased the number of small renal masses (SRMs) being diagnosed.(1, 2) While the majority of solid renal tumours measuring $\leq 4 \mathrm{~cm}$ are malignant, up to $30 \%$ are benign.(3) Additionally, most malignant SRMs are low-grade and have low-metastatic potential.(3) Initial definitive treatment of SRMs may represent overtreatment in many cases.

To justify and hopefully reduce overall treatment with its associated burden of care, renal tumour biopsy (RTB) has been proposed as a safe, accurate and reliable method to identify the histology of SRMs before treatment.(4-7) Although the use of active surveillance for SRMs is increasing, this strategy in surgical candidates could be refined based on RTB results. RTB could be helpful in identifying higher-metastatic potential tumours who are better suited for definitive treatment or by identifying histologically benign tumours which do not require a follow-up protocol as stringent as for malignant tumours.(8) Thus, although debatable, RTB can influence management. However, in spite of their potential benefits, many urologists are still reluctant to adopt RTB as a standard of care for SRMs.(9) Consequently, most SRMs are still treated(10) and RTBs remain under-utilized.(11, 12) Reasons for slow adoption of routine RTB are not well-understood, but may include concerns regarding non-diagnostic rates, discordance with final pathology, safety and a lack of perceived impact on clinical management.(9) These potential concerns have not been well supported by studies reported over the past few years. $(5,6)$

The objectives of this study were to characterize the uptake of RTB in Canada for the management of SRMs and to assess whether utilization rates varied between types of practice and training. Lastly, we aimed to better characterize the barriers to a greater adoption.

\section{Methods}

Following approval from the University Health Network Research Ethics Board, a pilot questionnaire was developed and tested in 20 urologists in May 2016. All items were then revised according to the responses in the pilot survey. The survey questions were formatted as either multiple choice, rating scale or short answer. An electronic survey was then generated (www.surveymonkey.com)(13) and distributed via email. The survey was 
distributed to all active members of the Canadian Urological Association (CUA) and the Quebec Urological Association (QUA). Two emails (one initial and one reminder) containing a link to the survey were sent out to all 767 members on June $13^{\text {th }}$ and 22th, 2016. Members of both associations were invited to answer a questionnaire in their language of preference (available in French and English). The survey contained questions regarding the physicians practice patterns, RTB utilization and potential barriers of RTB (Appendix 1). We excluded non-urologists, pediatric urologists, urologists who did not manage SRMs and physicians who gave incomplete demographic information or who did not answer questions beyond the demographic ones.

Continuous and categorical variables were reported using medians [interquartile range (IQR)] and proportions, respectively. Chi-squared tests were used to assess differences between specific groups of respondents (types of practice and fellowship training). To test whether different patient and tumour characteristics were associated with the likelihood of recommending a RTB, we performed paired McNemar's tests to determine whether responses within respondents differed based on presence or absence of each factor. Univariate and multivariate conditional logistic regression models, adjusted for interactions between variables and accounting for repeated subjects, were used to analyze the impact of age, comorbidity status and renal function on the likelihood of requesting a RTB. A Bonferroni correction (adjusted p value $=0.025$ ) was applied for multiple groups comparison, when required. All other statistical tests were two-sided and $\mathrm{p}$-values $<0.05$ were considered statistically significant. Statistical analyses were conducted in the R statistical environment, version 3.2.3 (R core team).(14)

\section{Results}

In total 223 members responded to the survey, resulting in a response rate of $29.1 \%$. From these, we excluded 12 because they did not provide data on their type of profession, 11 because they did not answer any questions other than the demographic ones and another 12 because they did not manage SRMs. Therefore, our study included 188 individuals. Demographic data is presented in Table 1. Of the eligible respondents, 69 (36.7\%) practiced in an academic center while 119 (63.3\%) practiced in a non-academic one. The median (IQR) number of new SRMs patients managed annually by the included respondents was 20 (12.5-30).

\section{Renal tumour biopsy utilization}

Of the eligible respondents, a minority (11.7\%) performed a RTB in greater than $75 \%$ of cases while $53.2 \%$ never performed or performed RTB in less than $25 \%$ of cases. There was no significance difference in the perceived use of RTB according to the type of urologic practice (Table 2). However, physicians with a urologic oncology fellowship were significantly more likely to request a biopsy than endourologists (Bonferroni adjusted 
$\mathrm{p}=0.01$ ) and physicians without fellowship-training or with a non-oncology/nonendourology fellowship (Bonferroni adjusted $\mathrm{p}=0.003$; Table 3).

When performed, nearly all respondents indicated that RTB was performed by a radiologist (96.2\%) and most used needle core biopsy (68.6\%) or a combination of fineneedle aspiration (FNA) and core biopsy (18.6\%). The majority also indicated that biopsies were performed on an outpatient basis (92\%). There was with no major differences in these parameters according to the type of practice, but some variation was observed according to the type of center (Tables 2 and 3).

Patient and tumour factors associated with recommending a biopsy

Several patient and tumour characteristics were associated with increased likelihood of recommending a biopsy (Table 4a). Physicians were more likely to recommend a biopsy for patients with a known family history of renal cell carcinoma, a known hereditary syndrome and if the patient's treatment preference was active surveillance or thermal ablation rather than surgery. Likewise, tumours that were solid, multifocal, and greater than $2 \mathrm{~cm}$ in maximal dimension were more likely to be biopsied than their counterparts. Physicians were also more inclined to biopsy low or minimally enhancing tumours more often than the highly enhancing ones. Endophytic tumours and the ones located near the hilum were less often biopsied than exophytic tumours.

Scenario questions: interactions between factors associated with recommending a biopsy Using a conditional multivariate logistic model, we identified that patients aged 70 to 75 years were more like to undergo biopsy than 50 to 65 years old whereas patients aged $\geq 80$ years were less likely to be biopsied. Patients with more medical comorbidities and decrease renal function were more likely to receive RTB than healthier patients (Table $4 \mathrm{~b}$ ).

When further evaluating the data, we identified several significant statistical interactions between the variables of age, comorbidity status and renal function. When considering patients aged 50 to 65 , poor renal function and the presence of multiple comorbidities increased the odds of requesting a RTB. In contrast when considering patients 70 to 75 years old, only the renal function status correlated with requesting a RTB. Lastly among patients $>75$, neither comorbidity nor renal function status influenced the likelihood of requesting a RTB (Appendix 1).

Barriers of routine adoption of RTB

Several potential management-, pathology- and radiology-related concerns were identified as barriers to routine adoption of RTB (Table 5). The most commonly reported management-related barrier was a belief that biopsy won't alter management (35.5\%) while the risk of obtaining a false-negative or a non-diagnostic biopsy was the greatest pathologyrelated barrier. Of the 4 proposed radiology-related concerns, a lack of expertise with RTB 
was the most cited concern, but $43 \%$ of the respondents felt that none of the radiologyrelated items were major barriers to a more widespread adoption of RTB.

\section{Discussion}

In the absence of liquid biomarkers or better imaging, there isn't a more robust diagnostic test than RTB to determine histology and guide a more personalized management of SRMs. In spite of the evidence supporting the role of RTB in the management of SRMs,(5-7, 1518) our survey confirms that many urologists in Canada do not routinely use RTB as a means to guide treatment for SRMs. Only a quarter of respondents indicated that they requested a RTB in more than $50 \%$ of cases, while more than half indicated that they never performed or only performed RTB in less than $25 \%$ of cases. Adoption rates were higher among urologic oncologists than among endourologists or urologists with no fellowshiptraining or with non-oncology/non-endourology fellowship training but did not differ between academic and non-academic urologists.

Despite the limited adoption of RTB to guide management of SRMs, proponents of RTBs have to be encouraged by our findings as the perceived use of RTB is higher than what had previously been reported in the literature. In 2012, Barwari et al, surveyed members of the Endourological Society, and reported that the majority of respondents (73\%) never or rarely perform RTBs and that only 9\% of them recommended a biopsy in more than 25\% of the cases.(11) Similarly, a Surveillance, Epidemiology, and End ResultsMedicare (SEER) database study from 1992-2007 demonstrated that although there was a modest rise in the use of RTB, the increase was primarily observed among patients with metastatic disease and those receiving percutaneous thermal-ablative therapies. Among patients with localized disease, the utilization rates of RTB in SEER remained fairly stable throughout the study period with RTBs being used in less than $20 \%$ of cases.(12)

This survey identified several patient and tumour characteristics that increased the likelihood that a physician recommends a RTB to inform treatment decision process. Not surprisingly, personal and familial history of cancer, treatment preference and a myriad of tumour characteristics impacted the likelihood that a physician requested a RTB. The study also highlights the fact that the treatment decision for SRM is a complex one and that several patient and tumour characteristics need to be considered.

Lastly, the survey evaluated several key barriers that physicians felt were preventing a greater adoption of RTB. In spite of being legitimate concerns, many of the identified barriers (diagnostic yield, eligibility, safety, generalizability outside of single-center studies, etc) have previously been shown to be unfounded, while others remains to be further investigated (i.e. benign histology concordance, impact of RTB on management). Recent reports have demonstrated that RTBs are an accurate and reliable tool to guide management of SRMs.(5-7) Additionally, a meta-analysis by Marconi et al. has demonstrated that initial RTBs yielded in diagnosis in $>90 \%$ of cases and that they had a high concordance with 
surgical pathology (96\%) for both histology and grade (66\% and $87 \%$ when using a 4 - and 2-tiered grading system, respectively).(5) Our group has also shown that a repeat biopsy has a similar diagnostic yield than the initial one indicating that technical factors are often the reason for a non-diagnostic biopsy.(6) Despite these reports, nearly half of the responders answered that the risk a false-negative or non-diagnostic biopsy was still a major deterrent to a more widespread adoption of RTB. Another common concern among urologists was that the safety, accuracy and reliability of RTBs were not replicable outside of centers with experience. However, a recent Canadian-based multicenter retrospective study has recently disproved this concern as the report demonstrated the safety (significant adverse events in $<1 \%$ ), reliability (histologic and 2-tiered grading system concordance with surgical pathology of $88 \%$ and $81 \%$, respectively) and accuracy (diagnostic yield $\approx 90 \%$ diagnostic yield) of RTB outside of a single-institution series.(17)

Most proponents of RTB believe that biopsying SRMs will lead to a decrease in unnecessary interventions by avoiding treatment of benign SRMs and of low-metastatic potential tumours.(19) However, this belief is not unanimously supported by the urologic community and it has not been validated in well-designed trials. As demonstrated by this report many urologists believe that a key barrier to a more widespread adoption of RTB is that they do not alter patient management. Similar concerns has been voiced a number of experts in the field.(9) Therefore, future studies evaluating the impact of RTB on SRM management will be key to determine the exact role of RTB in a SRM treatment decision algorithm.

This study is not devoid of limitations. Similar to Barwari's survey (10\% response rate)(11), our response rate was also low with a rate of only $29 \%$. This response rate could potentially be explained by the fact that the survey was sent to the email addresses of CUA and QUA members regardless of their level of training, type of practice and field interest. It is probable that non-urologists or urologists that did not treat adult and/or renal cancer were less likely to respond to the survey. Additionally, although several key potential barriers were proposed, the current survey did not allow for free text and thus, other additional key concerns may not have been appropriately captured. Nevertheless, in an era where overtreatment is gaining worldwide attention, $(20,21)$ this study provides insight on the use of RTB in the management of SRMs and on the potential barriers to its more widespread adoption. As demonstrated, many identified concerns have already been debunked and therefore, there seems to be a dire need for knowledge transfer strategies to improve the adoption of RTBs.

\section{Conclusion}

The adoption of RTB as a diagnostic test to identify pretreatment histology of SRMs remains low in Canada. Several barriers to a greater adoption of RTB have been identified, with the main ones being concerns over its accuracy and its ability to change clinical 
practice. Several of the identified concerns have already been addressed by previous reports, while others remains to be further investigated. Knowledge translation strategies are needed to inform urologists of the potential benefits and limitations of RTB. Further research is also essential to address the remaining knowledge gap and to evaluate where RTB is most valuable and how to best implement this tool. 


\section{References}

1. American Cancer Society. Cancer facts and figures, Atlanta, GA,2016 [cited 2017 May 16th]. American Cancer Society,:[Available from: http://www.cancer.org/.]

2. Hollingsworth JM, Miller DC, Daignault S, et al. Rising incidence of small renal masses: a need to reassess treatment effect. JNCI. 2006;98:1331-4.

3. Frank I, Blute ML, Cheville JC, et al. Solid renal tumours: An analysis of pathological features related to tumour size. J Urol. 2003;170:2217-20.

4. Leveridge MJ, Finelli A, Kachura JR, et al. Outcomes of small renal mass needle core biopsy, nondiagnostic percutaneous biopsy, and the role of repeat biopsy. Eur Urol. 2011;60:578-84.

5. Marconi L, Dabestani S, Lam TB, et al. Systematic review and meta-analysis of diagnostic accuracy of percutaneous renal tumour biopsy. Eur Urol. 2016; 69:660-73.

6. Richard PO, Jewett MAS, Bhatt JR, et al. Renal Tumour Biopsy for small renal masses: A single-center 13-year experience. Eur Urol. 2015;68:1007-13.

7. Patel HD, Johnson MH, Pierorazio PM, et al. Diagnostic accuracy and risks of biopsy in the diagnosis of a renal mass suspicious for localized renal cell carcinoma: Systematic review of the literature. J Urol. 2016;epub.

8. Leao RR, Ahmed A, Richard PO. Should small renal masses be biopsied. Curr Urol Rep. 2017;18:7.

9. Kutikov A, Smaldone MC, Uzzo RG, et al. Renal mass biopsy: Always, sometimes, or never? Eur Urol. 2016;70: 403-06.

10. Huang WC, Atoria CL, Bjurlin M, et al. Management of small kidney cancers in the new millennium: Contemporary trends and outcomes in a population-based cohort. JAMA Surg. 2015;150:664-72.

11. Barwari K, de la Rosette J, Laguna MP. The penetration of renal mass biopsy in daily practice: A survey among urologists. J Endourol. 2012;26:737-47.

12. Leppert JT, Hanley J, Wagner TH, et al. Utilization of renal mass biopsy in patients with renal cell carcinoma. Urology. 2014;83:774-9.

13. SurveyMonkey - Free online survey software \& questionnaire tool [cited 2016 June]. Available from: www.surveymonkey.com.

14. R Core Team. R: A language and environment for statistical computing. R Foundation for Statistical Computing, Vienna, Austria. 2015.

15. Jewett MA, Richard PO, Finelli A. Management of small renal mass: An opportunity to address a growing problem in early stage kidney cancer. Eur Urol. 2015;68:416-7.

16. Menogue SR, O’Brien BA, Brown AL, et al. Percutaneous core biopsy of small renal mass lesions : a diagnostic tool to better stratify patients for surgical intervention. BJU Int. 2013;111:E146-51. 
17. Richard PO, Jewett MA, Tanguay S, et al. Safety, reliability and accuracy of small renal tumour biopsies: results from a multi-institution registry. BJU Int. 2017; 119:543:49.

18. Volpe A, Finelli A, Gill IS, et al. Rationale for Percutaneous Biopsy and Histologic Characterisation of Renal Tumours. Eur Urol. 2012;62:491-504.

19. Richard PO, Jewett MA, Finelli A. Alexander Kutikov, Marc C. Smaldone, Robert G. Uzzo, Miki Haifler, Gennady Bratslavsky, Bradley C. Leibovich. Renal Mass Biopsy: Always, Sometimes, or Never? Eur Urol. 2017; 71:e45-6.

20. Esserman LJ, Thompson IM, Reid B. Overdiagnosis and overtreatment in cancer: An opportunity for improvement. JAMA. 2013;310:797-8.

21. Daskivich TJ, Tna HJ, Litwin MS, Hu JC. Life expectancy and variation in treatment for early stage kidney cancer. J Urol. 2016;196:672-7. 
Figures and Tables

\begin{tabular}{|l|c|}
\hline \multicolumn{2}{|c|}{ Table 1. Demographic data of the included respondents (n=188) } \\
\hline Variables & $\mathbf{n ~ ( \% )}$ \\
\hline Current profession & $178(94.7)$ \\
$\quad$ Adult urology & $10(5.3)$ \\
Urology resident/fellow & \\
\hline Years in practice & $52(27.7)$ \\
$0-5$ & $38(20.2)$ \\
$6-10$ & $24(12.8)$ \\
$11-15$ & $72(38.3)$ \\
$>15$ & $2(1.1)$ \\
Practice under supervision & \\
\hline Fellowship training & $48(25.5)$ \\
Urologic oncology & $43(22.9)$ \\
Endourology/minimally invasive & $27(14.4)$ \\
surgery & $70(37.2)$ \\
Other fellowship & \\
No fellowship training & \\
\hline Type of practice & $69(36.7)$ \\
Academic hospital & $44(23.4)$ \\
University-affiliated hospital & $75(39.9)$ \\
Community or rural hospital & \\
\hline Annual number of new SRMs & $26 \pm 27$ \\
consultation, mean \pm SD & $40 \pm 21.3$ \\
$1-10$ & $61 \pm 32.4$ \\
$11-20$ & $45 \pm 23.9$ \\
$21-30$ & $42 \pm 22.3$ \\
\hline 30 &
\end{tabular}

SD: standard deviation; SRMs: small renal massed. 


\section{Table 2. Renal tumour biopsy utilization: Overall and per type of practice}

\begin{tabular}{|c|c|c|c|c|}
\hline Questions & $\begin{array}{l}\text { Overall } \\
(\mathrm{n}=188)\end{array}$ & $\begin{array}{c}\text { Academic } \\
(n=69)\end{array}$ & $\begin{array}{c}\text { Non-academic } \\
(\mathrm{n}=119)\end{array}$ & $\mathbf{p}$ \\
\hline $\begin{array}{l}\text { In what proportion of patients with } \\
\text { SRM do you request a RTB to } \\
\text { inform treatment? } \\
\text { Never } \\
\leq 25 \% \text { of cases } \\
26-50 \% \text { of cases } \\
51-75 \% \text { of cases } \\
76-100 \% \text { of cases }\end{array}$ & $\begin{array}{l}13(6.9) \\
87(46.3) \\
40(21.3) \\
26(13.8) \\
22(11.7)\end{array}$ & $\begin{array}{l}2(2.9) \\
30(43.5) \\
14(20.3) \\
12(17.4) \\
11(15.9)\end{array}$ & $\begin{array}{l}11(9.2) \\
57(47.9) \\
26(21.9) \\
14(11.8) \\
11(9.2)\end{array}$ & $\begin{array}{l}0 \\
2 \\
2\end{array}$ \\
\hline $\begin{array}{l}\text { What type of biopsy is typically } \\
\text { performed at your centre? } \\
\text { Fine needle aspiration (FNA) } \\
\text { Needle core biopsy } \\
\text { Both FNA and core biopsy } \\
\text { punctures } \\
\text { Biopsies are not performed or I } \\
\text { am unsure }\end{array}$ & $\begin{array}{c}7(3.7) \\
129(68.6) \\
35(18.6) \\
17(9.0)\end{array}$ & $\begin{array}{c}4(5.8) \\
54(78.3) \\
10(6.9) \\
1(1.5)\end{array}$ & $\begin{array}{c}3(2.5) \\
75(63.0) \\
25(21.0) \\
16(13.5)\end{array}$ & 0.01 \\
\hline $\begin{array}{l}\text { Who typically performs these } \\
\text { RTBs? } \\
\text { Radiologist } \\
\text { Urologist } \\
\text { Urologist/radiologist } \\
\text { Biopsies are not performed at } \\
\text { our centre }\end{array}$ & $\begin{array}{c}180(95.7) \\
1(0.5) \\
1(0.5) \\
6(3.2)\end{array}$ & $\begin{array}{c}67(97.1) \\
1(1.5) \\
1(1.5) \\
0(0)\end{array}$ & $\begin{array}{c}113(95.0) \\
0(0) \\
0(0) \\
6(5.0)\end{array}$ & 0.07 \\
\hline $\begin{array}{l}\text { Following RTB, patients are } \\
\text { typically: } \\
\text { Hospitalized overnight } \\
\text { Discharged on the same day } \\
\text { (outpatient) } \\
\text { Other }\end{array}$ & $\begin{array}{c}8(4.3) \\
173(92.0) \\
7(3.7)\end{array}$ & $\begin{array}{c}0(0) \\
68(98.6) \\
1(1.4)\end{array}$ & $\begin{array}{c}8(6.7) \\
105(88.2) \\
6(5.0)\end{array}$ & 0.04 \\
\hline
\end{tabular}

RTB: renal tumour biopsies SRMs: small renal massed. 
Table 3. Renal tumour biopsy utilization: Overall and per fellowship training

\begin{tabular}{|c|c|c|c|c|c|}
\hline \multirow[b]{2}{*}{ Questions } & \multirow[b]{2}{*}{$\begin{array}{l}\text { Overall } \\
(n=188)\end{array}$} & \multicolumn{3}{|c|}{ Type of fellowship training } & \multirow[b]{2}{*}{$\mathbf{p}$} \\
\hline & & $\begin{array}{c}\text { Urologic } \\
\text { oncology } \\
(n=48)\end{array}$ & $\begin{array}{c}\text { Endourology } \\
\text { /MIS } \\
(\mathbf{n}=43)\end{array}$ & $\begin{array}{c}\text { Other } \\
\text { fellowship/ } \\
\text { none } \\
(\mathbf{n}=97)\end{array}$ & \\
\hline \multicolumn{6}{|l|}{$\begin{array}{l}\text { In what proportion of patients with SRM do you } \\
\text { request a RTB to inform treatment? }\end{array}$} \\
\hline Never & $13(6.9)$ & $0(0)$ & $3(7.0)$ & $10(10.3)$ & $0.01^{*}$ \\
\hline$\leq 25 \%$ of cases & $87(46.3)$ & $14(29.2)$ & $23(53.5)$ & $50(51.6)$ & \\
\hline $26-50 \%$ of cases & $40(21.3)$ & $15(31.3)$ & 7 (16.3) & $18(18.6)$ & \\
\hline $51-75 \%$ of cases & $26(13.8)$ & $11(22.9)$ & $3(7.0)$ & $12(12.4)$ & \\
\hline 76--100\% of cases & $22(11.7)$ & $8(16.7)$ & $7(16.3)$ & $7(7.2)$ & \\
\hline \multicolumn{6}{|c|}{$\begin{array}{l}\text { What type of biopsy is typically performed at your } \\
\text { centre? }\end{array}$} \\
\hline Fine needle aspiration (FNA) & $7(3.7)$ & $0(0)$ & $3(7.0)$ & $4(4.1)$ & $0.7^{\dagger}$ \\
\hline Needle core biopsy & $129(68.6)$ & 42 (87.5) & $29(67.4)$ & $58(59.8)$ & \\
\hline Both FNA and core biopsy punctures & 35 (18.6) & $6(12.5)$ & $6(14.0)$ & $23(23.7)$ & \\
\hline Biopsies are not performed or I am unsure & $17(9.0)$ & $0(0)$ & $5(11.6)$ & $12(12.4)$ & \\
\hline Who typically performs these RTBs? & & & 2 & & 0.07 \\
\hline Radiologist & $180(95.7)$ & $46(95.8)$ & $43(100)$ & $91(93.8)$ & \\
\hline Urologist & $1(0.5)$ & $1(2.1)$ & $0(0)$ & $0(0)$ & \\
\hline Urologist/radiologist & $1(0.5)$ & $1(2.1)$ & $0(0)$ & $0(0)$ & \\
\hline Biopsies are not performed at our centre & $6(3.2)$ & $0(0)$ & $0(0)$ & $6(6.2)$ & \\
\hline Following RTB, patients are typically: & & & & & $0.1^{\ddagger}$ \\
\hline Hospitalized overnight & $8(4.3)$ & $0(0)$ & $2(4.7)$ & $6(6.2)$ & \\
\hline Discharged on the same day (outpatient) & $173(92.0)$ & $48(100)$ & $41(95.4)$ & $84(86.6)$ & \\
\hline Other/missing & 7 (3.7) & $0(1.4)$ & $0(2.3)$ & $7(7.2)$ & \\
\hline
\end{tabular}

*Bonferroni adjusted $\mathrm{p}$ value urologic oncology vs. endourology $=0.01$; Bonferroni adjusted $\mathrm{p}$ value urologic oncology vs. other fellowship/none $=0.003$. If category "biopsies are not performed or I am unsure" considered in the analysis, $\mathrm{p}=0.02 .{ }^{\ddagger}$ If "Other/missing" considered in the analysis, $\mathrm{p}=0.04$. RTB: renal tumour biopsies SRMs: small renal massed. 


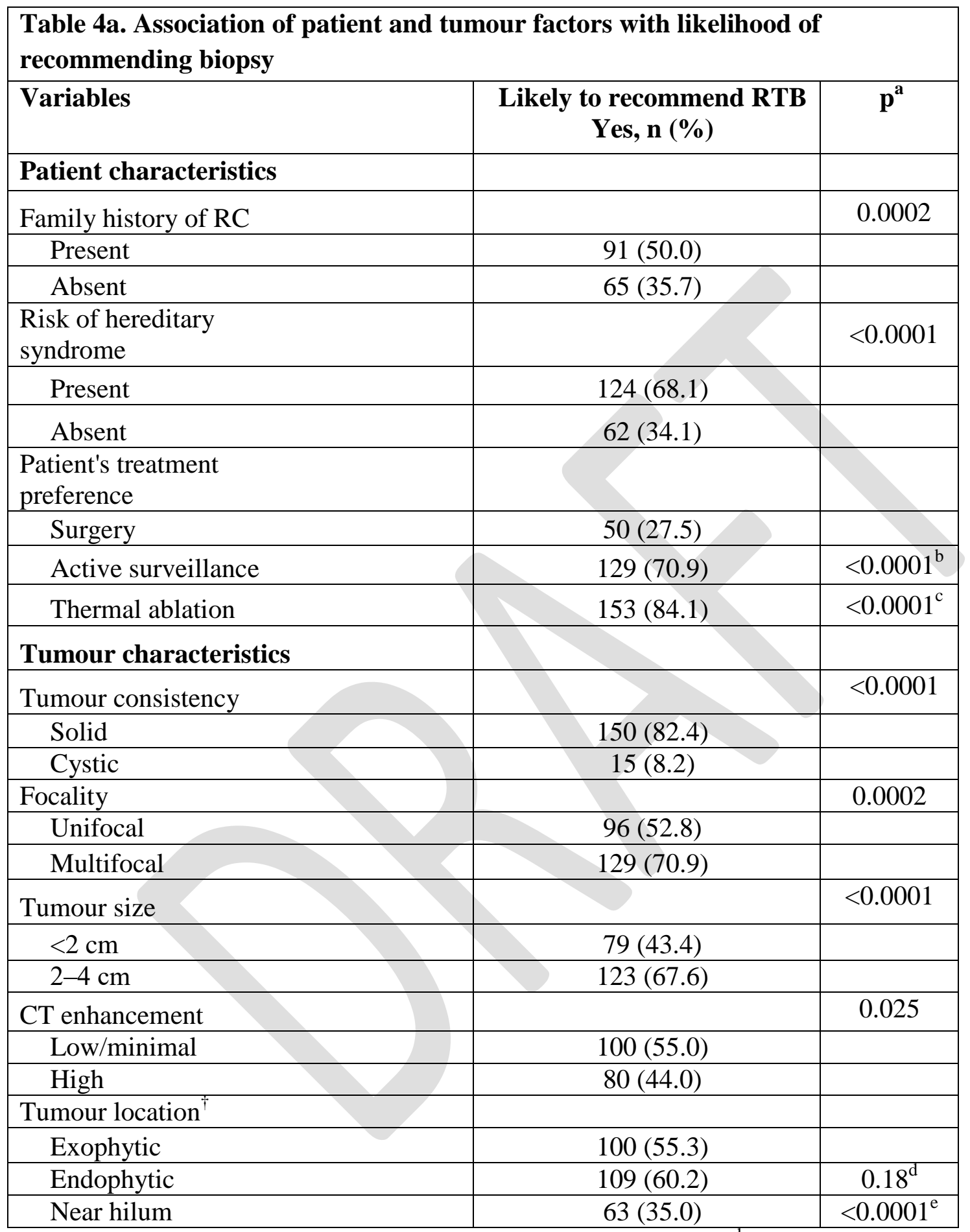

${ }^{\mathrm{a}} \mathrm{p}<0.05$ indicates that the factor influences the decision to biopsy. ${ }^{\mathrm{b}}$ Surgery compared to AS. 'Surgery compared to ablation. ${ }^{\mathrm{d}}$ Exophytic compared to endophytic. ${ }^{\mathrm{e}}$ Exophytic compared to near the hilum. 


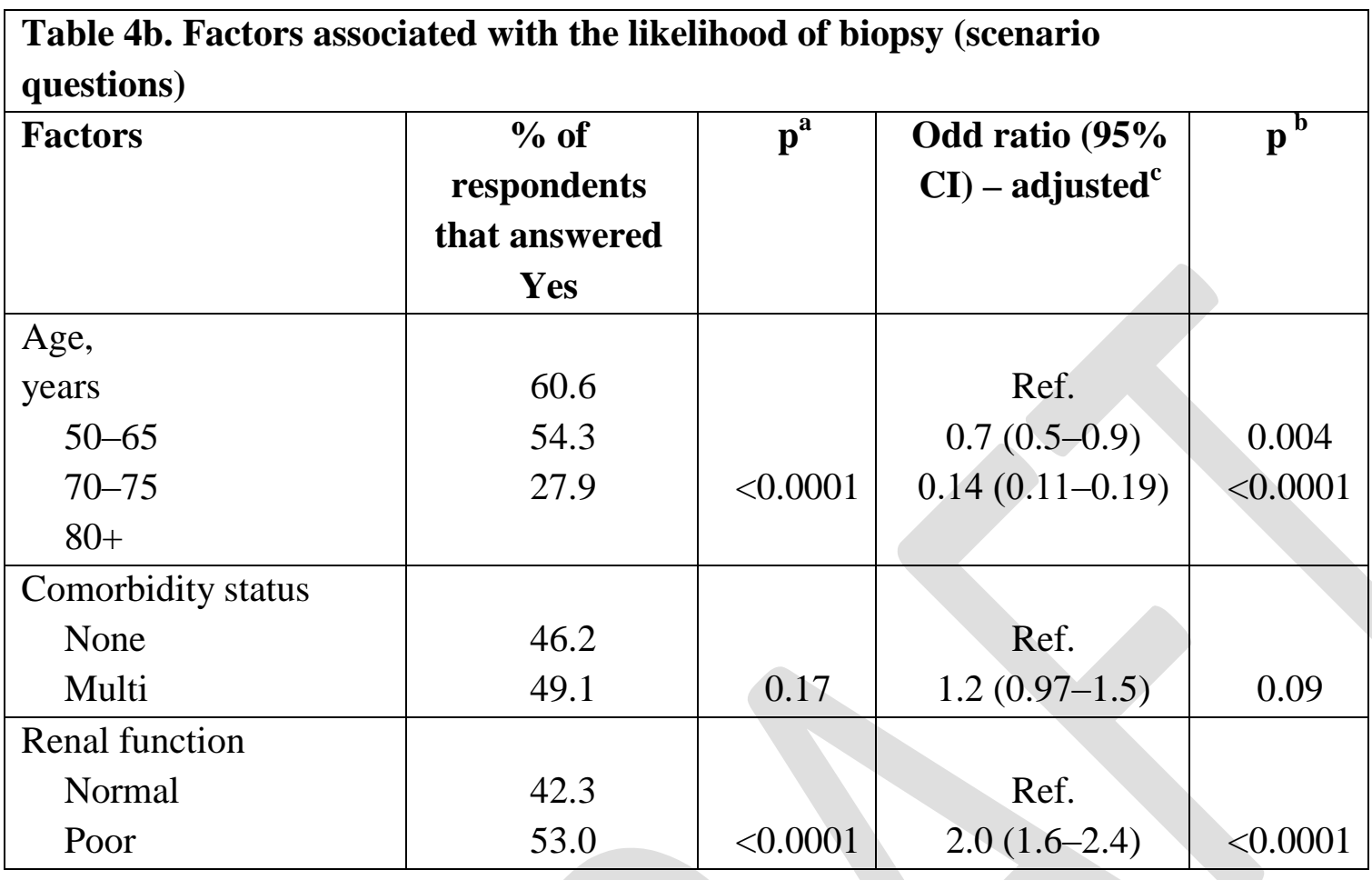

${ }^{\mathrm{a}} \mathrm{p}$ calculated from conditional logistic regression (accounting for repeated subjects).

${ }^{\mathrm{b}}$ Odds ratio and $\mathrm{p}$ calculated from a conditional logistic regression model including age, comorbidity status, and renal function as main effects only. CI: confidence interval. 
Table 5. Barriers to more widespread adoption of renal tumour biopsy

\begin{tabular}{|c|c|c|}
\hline Concerns & $\begin{array}{c}\text { Statement } \\
\text { reported } \\
\text { as being a } \\
\text { concern, } \\
\text { n }(\%)\end{array}$ & $\begin{array}{c}\text { Statement } \\
\text { reported } \\
\text { as being } \\
\text { the } \\
\text { greatest } \\
\text { concern, } \\
\text { n (\%) }\end{array}$ \\
\hline $\begin{array}{l}\text { Management-related concerns } \\
\text { - Current safety, accuracy and reliability } \\
\text { of RTB are not replicable outside of } \\
\text { centres with experience } \\
\text { - Biopsy results won’t alter management } \\
\text { - Don't see need to biopsy because we } \\
\text { have a low rate of overtreatment at our } \\
\text { centre } \\
\text { - Patient's concerns regarding the safety } \\
\text { - } \text { and/or benefits of renal tumour biopsy } \\
\text { None of the above is a barrier/Other }\end{array}$ & $\begin{array}{c}75(44.4) \\
89(52.7) \\
66(39.1) \\
54(32.0) \\
n / a\end{array}$ & $\begin{array}{c}41(24.3) \\
60(35.5) \\
16(9.5) \\
13(7.7) \\
39(23.1)\end{array}$ \\
\hline $\begin{array}{l}\text { Pathology-related concerns }{ }^{\dagger} \\
\text { - Lack of concordance between renal } \\
\text { tumour biopsy histology and surgical } \\
\text { histology (malignant) } \\
\text { - } \text { Risk of false-negative or non- } \\
\text { diagnostic biopsy } \\
\text { - } \\
\text { Lack of grade concordance between } \\
\text { renal tumour biopsy and surgical } \\
\text { specimen } \\
\text { - Lack of evidence supporting } \\
\text { concordance for benign histology } \\
\text { between renal tumour biopsy and } \\
\text { surgical pathology } \\
\text { - We don’t have an expert uro- } \\
\text { pathologist at our centre } \\
\text { None of the above is a barrier }\end{array}$ & $\begin{array}{c}44(26.5) \\
106(63.9) \\
47(28.3) \\
56(33.7) \\
44(25.1) \\
n / a\end{array}$ & $\begin{array}{c}12(7.2) \\
75(45.2) \\
2(1.2) \\
22(13.3) \\
10(6.0) \\
45(27.1)\end{array}$ \\
\hline Radiology-related concerns $^{\ddagger}$ & & \\
\hline
\end{tabular}




\begin{tabular}{|c|c|c|c|c|c|c|c|}
\hline $\begin{array}{l}\text { ar } \\
\text { s } \\
5 \\
0- \\
05 \\
65 \\
7 \\
0- \\
75 \\
\geq \\
80\end{array}$ & & $\mathrm{~A}$ & & $\begin{array}{l}( \\
0 \\
. \\
8 \\
- \\
1 \\
. \\
7 \\
) \\
0 \\
. \\
3 \\
( \\
0\end{array}$ & $\begin{array}{l}( \\
0 \\
. \\
3 \\
- \\
0 \\
. \\
6 \\
) \\
0 \\
. \\
0 \\
8 \\
( \\
0 \\
0 \\
0 \\
0 \\
5 \\
- \\
0 \\
. \\
1 \\
2 \\
)\end{array}$ & $\begin{array}{l}0 \\
. \\
9 \\
( \\
0 \\
. \\
6 \\
- \\
1 \\
. \\
3 \\
) \\
0 \\
. \\
3 \\
( \\
0 \\
. \\
2 \\
- \\
0 \\
. \\
4 \\
)\end{array}$ & $\begin{array}{l}( \\
0 \\
. \\
3 \\
- \\
0 \\
. \\
7 \\
) \\
0\end{array}$ \\
\hline $\begin{array}{l}\text { C } \\
\text { o } \\
\text { m } \\
\text { or } \\
\text { bi } \\
\text { di } \\
\text { tie } \\
\text { s }\end{array}$ & $\begin{array}{l}\mathrm{R} \\
\mathrm{E} \\
\mathrm{F} \\
2\end{array}$ & $\begin{array}{l}\mathrm{R} \\
\mathrm{E} \\
\mathrm{F} \\
0 \\
\dot{8}\end{array}$ & $\begin{array}{l}\mathrm{R} \\
\mathrm{E} \\
\mathrm{F} \\
0 \\
.\end{array}$ & & & $\begin{array}{l}\mathrm{R} \\
\mathrm{E} \\
\mathrm{F} \\
1 \\
\dot{8} \\
\dot{8}\end{array}$ & $\begin{array}{l}\mathrm{R} \\
\mathrm{E} \\
\mathrm{F} \\
0\end{array}$ \\
\hline
\end{tabular}




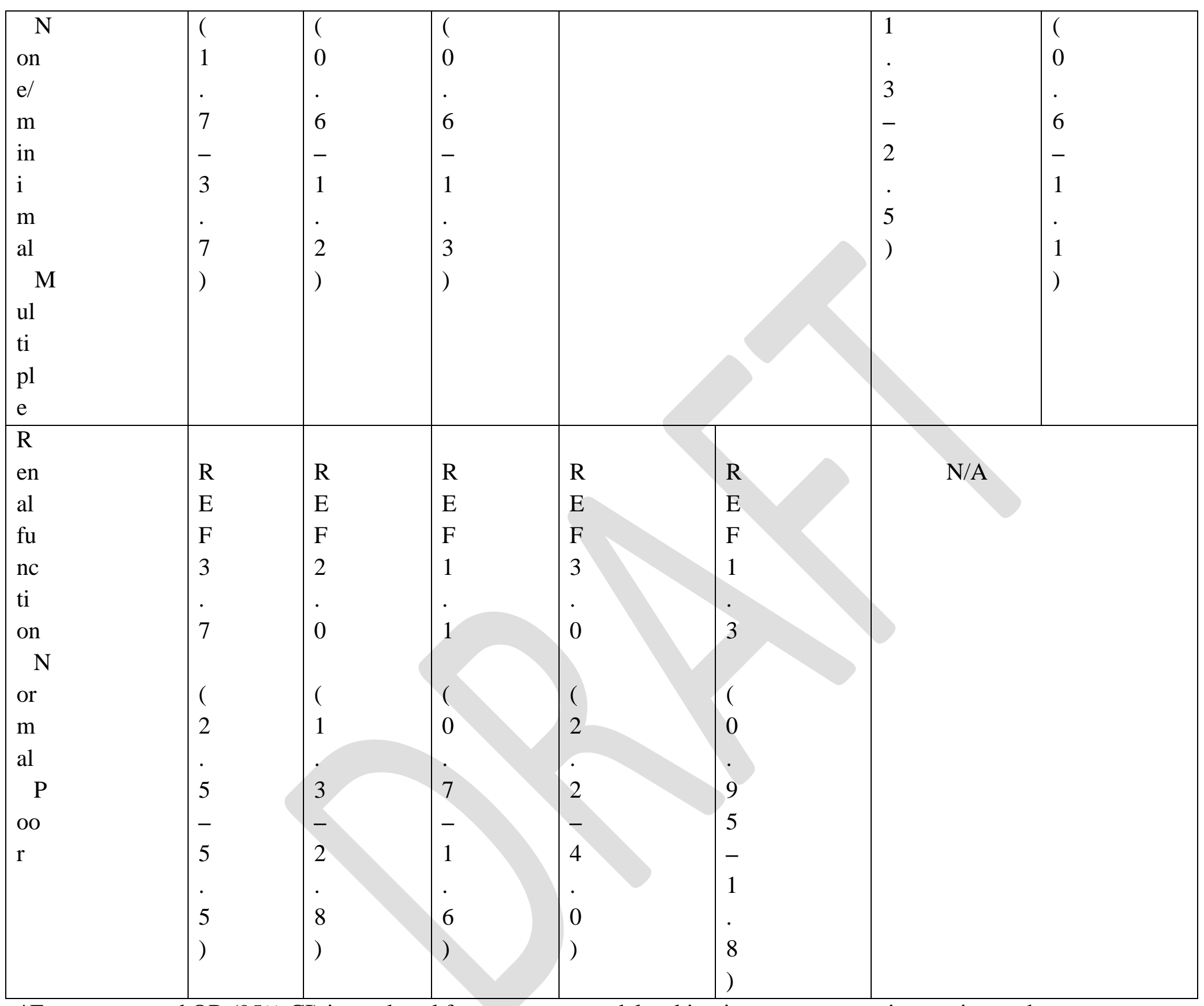

*Every presented OR $(95 \% \mathrm{CI})$ is produced from separate models taking into account one interaction at the time while adjusting for the other variable. CI: confidence interval; OR: odds ratio. 